MINERALOGIA, 48, No 1-4: 145-156 (2017)

DE DE GRUYTER OPEN

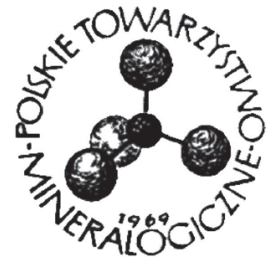

Original paper

\title{
The removal of organic compounds by natural and synthetic surface-functionalized zeolites: a mini-review
}

\author{
Barbara Muir ${ }^{1}$, Magdalena Wołowiec ${ }^{2 *}$, Tomasz Bajda ${ }^{2}$, Paulina Nowak ${ }^{1}$, \\ Piotr Czupryński ${ }^{1}$ \\ ${ }^{1}$ EDF Polska S.A., Department of Research and Development, ul. Cieplownicza 1, 31-587 Kraków, Poland \\ ${ }^{2}$ AGH University of Science and Technology in Kraków, 30 Mickiewicza Av., 30-059 Kraków, Poland \\ * Corresponding author \\ e-mail:wolowiec@agh.edu.pl
}

Received: May 9, 2017

Received in revised form: August 29, 2017

Accepted: August 30, 2017

Available online: September 30, 2017

\begin{abstract}
The use of zeolites as sorbents has been investigated as a replacement for existing costly methods of removing organic contaminants from water solutions. Zeolites can be modified by inorganic salts, organic surfactants, metals or metal oxides in order to increase their adsorption capacity. The unique ion exchange and adsorption properties of zeolites make them very suitable for application in the removal of organic compounds such as volatile organic compounds (VOCs), polycyclic aromatic hydrocarbons (PAHs), phenols and other complex petrochemicals. Many different studies have demonstrated their effectiveness in reducing the concentrations of organic contaminants as well as petroleum derivatives in water, which has been summarized in this paper.
\end{abstract}

Key-words: organo-zeolites; volatile organic compounds; surface modification; petroleum derivatives

\section{Introduction}

All over the world, water is exposed to pollution, with chemically clean water only being found in laboratories after distillation processes. Natural environmental processes, human activities and industry cause a significant amount of chemical substances to be dispersed into water. Organic compounds are one of the most common contaminants in water systems (Fig. 1). These contaminants may take decades to degrade and pose a threat to public health and the environment (Qin et al. 2008). The major categories of organic 
contaminants in water systems are volatile organic compounds (VOCs) and synthetic organic chemicals (Hariharan 2006).

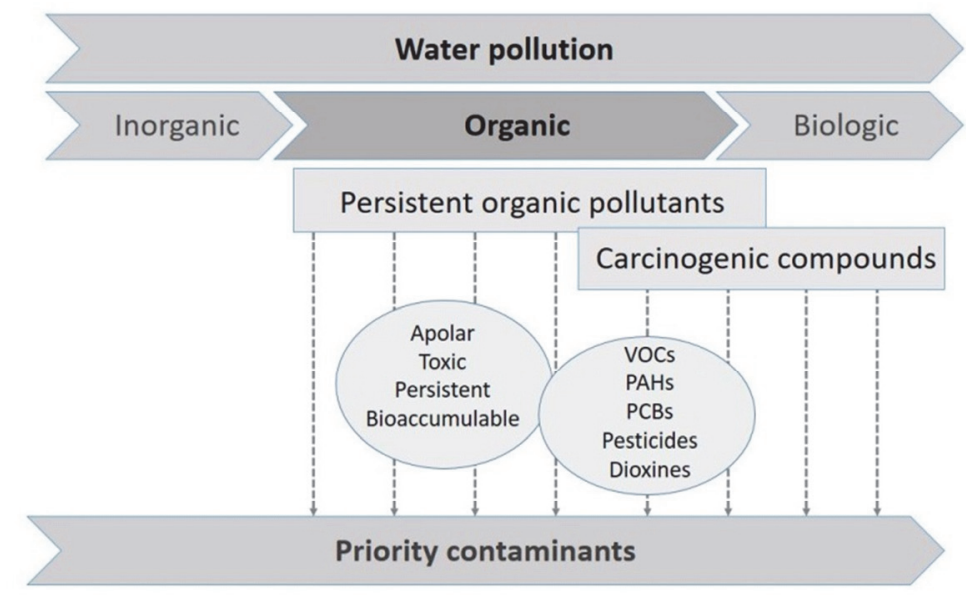

Fig. 1. Contamination of water resources, particularly-organic compounds.

Several treatment methods have been developed to remove those contaminants from industrial wastewater, including ion-exchange, filtration, adsorption and the use of various types of sorbents (Kibazohi et al. 2004; Mathur et al. 2007; Aivaliotiet al. 2012; Almeida et al. 2012). Research conducted by scientists around the world on the sorption properties of organo-minerals has proved that zeolites may be an appropriate substance to aid in the sorption of organic compounds (Zhao, Vance 1998; Meininghaus, Prins 2000; Lee, Tiwari 2012; Xie et al. 2013; Szala et al. 2015; Muir et al. 2016a; Bandura et al. 2017a). Zeolites are environmentally and economically viable hydrated aluminosilicate materials with exceptional ion-exchange and sorption properties (Margeta et al. 2013). Zeolites are characterized by very good ion-exchange capacity and exhibit a high affinity with the cationic form. The zeolite package is characterized by a negative overall charge. Therefore, all cations are willingly adsorbed on their surface ( $\mathrm{Li}$, Bowman 1998). These properties are determined by some of the quadri-charged silicon cations that are replaced by triplycharged aluminum, giving rise to a deficiency in positive charge. Therefore, zeolites exhibit a weak affinity with the anionic forms of metals as well as organic compounds, which limits their use. However, zeolites can be chemically modified by inorganic salts or organic surfactants, which are adsorbed on the surface and lead to the generation of positively charged oxi-hydroxides or surfactant micelles, which enables the zeolite to bind anions and organic compounds (Fig. 2) (Margeta et al. 2013).

In the past 45 years, synthetic analogues of natural zeolites have revolutionized aspects of the water treatment industry. Synthetic zeolites have been found to be useful in the removal of organic compounds from aqueous solutions, as well as in petroleum compound spillage cleanup (Bandura et al. 2017a). The chemistry of zeolite synthesis is subject to perturbations by impurities present in the source material (Alkan et al. 2005). Depending on 
the zeolite being synthesized and the application intended for the product, less pure source materials such as fly ash are frequently used, in order to reduce the cost (Franus et al. 2014). Synthetic zeolites can be formed through a reaction of sodium silicate, sodium aluminate clay minerals and coal combustion products with various sources of alkaline environment (Querol et al. 1995; Derkowski et al. 2007; Franus, Wdowin 2010; Gatta et al. 2012).

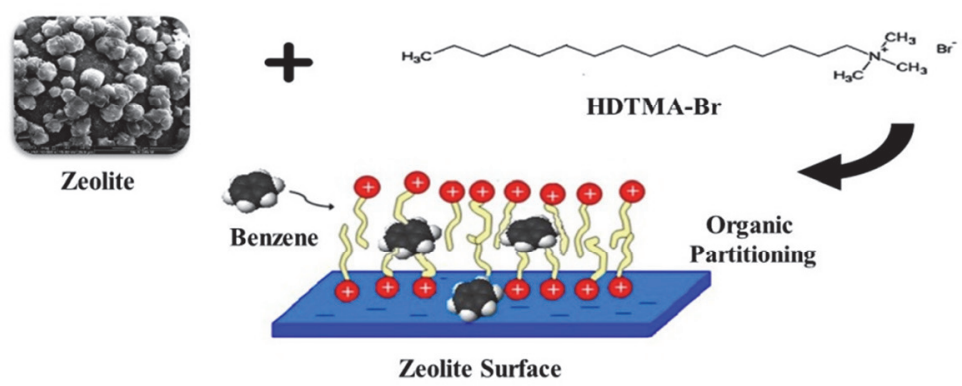

Fig. 2. Schematic diagram of zeolite's surface modification using quaternary ammonium salts (Ranck et al. 2005).

Most investigations conducted in the past were focused on the preparation of surfacefunctionalized zeolites for the removal of benzene, toluene, ethylbenzene and xylene (BTEX) compounds. In this paper, the use of zeolites to remove much wider groups of organic and petroleum compounds will be described. Due to the scarcity of consistent information on costs, such comparisons are difficult to make, and will therefore not be the objective of this study. In the area of zeolite application in organic compounds' removal, many outcomes and results have been accomplished; however, work is still necessary to better understand the adsorption mechanism and to develop and demonstrate technology that allows the dissemination of zeolites to the market of organic sorbents.

\section{Materials}

In this review some examples of natural zeolites (clinoptilolite and mordenite), synthetic zeolites (Na-P1, Na-Y, Na-X) and advanced zeolitic materials (zeolite foam, metal organic framework (MOF) foam) have been compiled. One of the most abundant minerals in the zeolite family is clinoptilolite - a natural, non-toxic zeolite that exhibits a monoclinic crystal structure symmetry and is characterized by high adsorption and ion exchange capacity (Mansouri et al. 2013). Its properties have been largely exploited in wastewater treatment (Grce, Pavelić 2005), especially in organic compounds' removal (Kuleyin 2006; Lemić et al. 2007; Bandura et al. 2015; Muir, Bajda 2016). Mordenite is also a widely distributed natural zeolite, characterized with high $\mathrm{Si}$ and $\mathrm{Al}$ content of the framework (Itabashi et al. 1986). Ever since mordenite was synthesized (Sand 1968), it has been known that some synthetic mordenite can accept cations or molecules larger than $4.5 \AA$, while natural mordenite cannot. In the literature, there are examples of using natural 
mordenite in the removal of humic acid, phenol and naphthalene (Xie et al. 2013). In recent years, the possibility of using fly ash for the synthesis of zeolites has been examined (Franus et al. 2014). The resulting synthetic zeolites possess very good sorption properties, a high surface area and stability in organic and inorganic media. Hydrothermal synthesis of fly ash with a solution of $\mathrm{NaOH}$ at a high temperature brings a high-purity zeolite and has been adapted to the industrial production of zeolites on a large scale (Franus et al. 2014). The resultant synthetic zeolites possess a much higher surface area and better sorption properties in comparison to clinoptilolite (Muir et al. 2016b, Table 1). The phase composition and morphology of the natural and synthetic zeolite surface are diametrically opposed (Fig. 3).
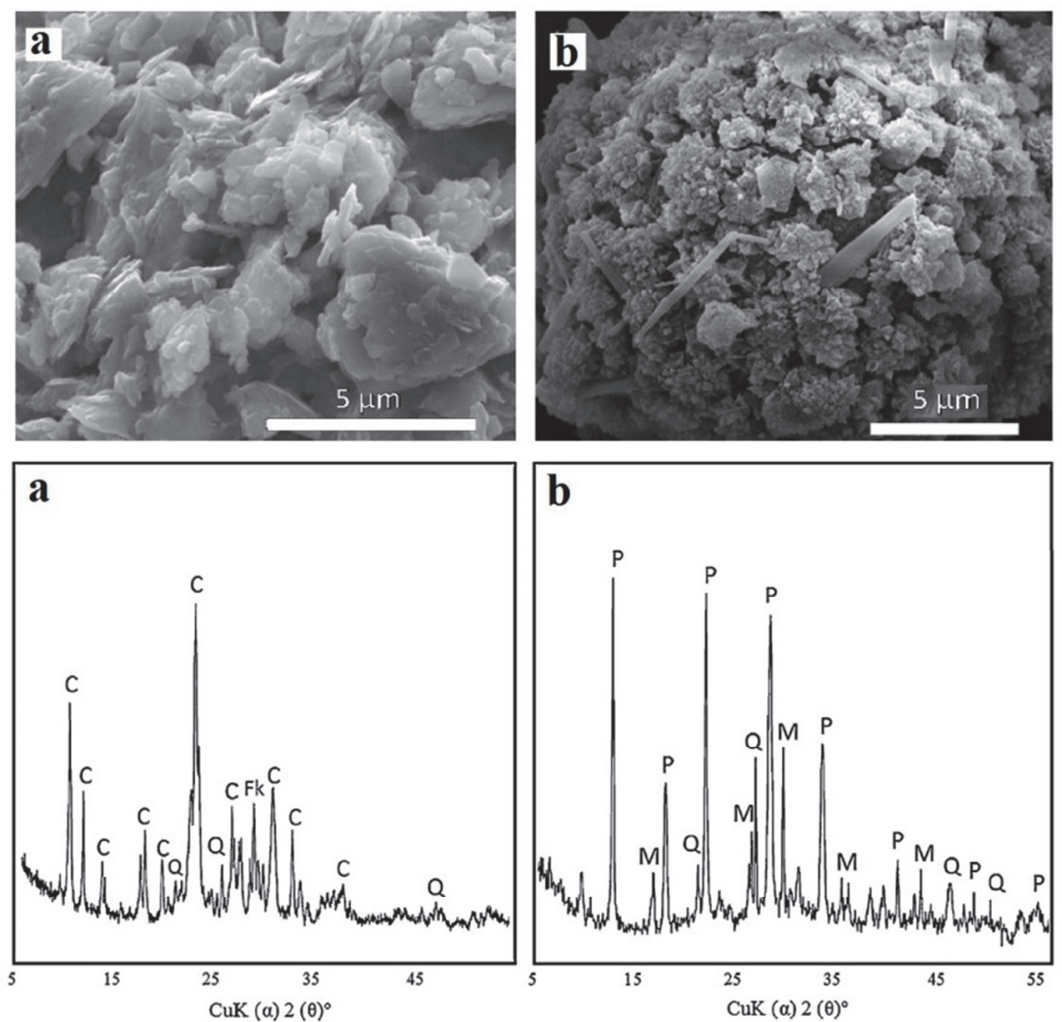

Fig. 3. Comparison of the surface morphology and phase composition of natural zeolite clinoptilolite and synthetic Na-P1 zeolite (Muir et al. 2016 a, b). C - clinoptilolite; Fk - potassium feldspar; Q - quartz; P - Na-P1 phase; M - mullite.

The sorption process of organic substances on zeolites is limited by the negativelycharged surface of their crystallites (Szala et al. 2015). In order to increase the chemical affinity of the zeolite's surface, organic compounds were used in the modification process. The process involves the replacement of naturally occurring exchangeable $\mathrm{K}^{+}, \mathrm{Na}^{+}, \mathrm{Ca}^{2+}$ and $\mathrm{Mg}^{2+}$ cations by organic cations (Fig. 2). This exchange neutralizes the negative charge, 
but should not reverse it (Bowman 2003). Surfactant modification alters the chemistry of the zeolite's surface drastically, allowing the adsorption of non-polar organic solutes and anions, for which untreated zeolites have little affinity (Apreutesei et al. 2008).

TABLE 1

Comparison of textural parameters of natural zeolite - clinoptilolite and synthetic Na-P1 zeolite (Muir et al. 2016 b).

\begin{tabular}{llllll}
\hline & $\mathbf{S}_{\text {BET }}$ & $\mathbf{V}_{\text {tot0.99 }}$ & $\mathbf{V}_{\text {mic }}$ & $\mathbf{V}_{\text {mes }}$ & $\mathbf{V}_{\text {mac }}$ \\
\hline Clinoptilolite & 15.88 & 0.047 & 0.006 & 0.027 & 0.014 \\
Na-P1 & 74.91 & 0.225 & 0.030 & 0.161 & 0.034 \\
\hline
\end{tabular}

$\mathrm{S}_{\mathrm{BET}}$ - specific surface area, $\left[\mathrm{m}^{2} / \mathrm{g}\right] ; \mathrm{V}_{\mathrm{tot}}$ - total pore volume $\left[\mathrm{cm}^{3} / \mathrm{g}\right] ; \mathrm{V}_{\text {mic }}$ - volume of micropores $\left[\mathrm{cm}^{3} / \mathrm{g}\right] ; \mathrm{V}_{\mathrm{mes}}-$ volume of mesopores $\left[\mathrm{cm}^{3} / \mathrm{g}\right] ; \mathrm{V}_{\mathrm{mac}}-$ volume of macropores $\left[\mathrm{cm}^{3} / \mathrm{g}\right]$.

\section{Results and Discussion}

\subsection{Clinoptilolite}

Sorption of phenol and 4-chlorophenol on clinoptilolite modified by hexadecyl trimethyl ammonium bromide (HDTMA) and benzyl tetradecyl ammonium bromide (BDTDA) was examined by Kuleyin (2006). An appropriate amount of phenol was added to $50 \mathrm{~mL}$ of the solution in a concentration range of $10-50 \mathrm{mg} \mathrm{kg}^{-1}$ for phenol and 10 $100 \mathrm{mg} \mathrm{kg}^{-1}$ for 4-chlorophenol. The mixture was shaken for $24 \mathrm{~h}$, then centrifuged. The concentration of phenol was determined by a UV-vis spectrophotometer. The higher the adsorbent dosage, the greater the amount of removed organic compound. The temperature is one of the factors which increases the sorption in the case of phenol. In the case of HDTMA-clinoptilolite, the phenol and 4-chlorophenol sorption capacities varied from 0.3 $0.4 \mathrm{mg} \mathrm{g}^{-1}$ and from $1.6-2.1 \mathrm{mg} \mathrm{g}^{-1}$, respectively. BDTDA-clinoptilolite removed phenol and 4-chlorophenol in the amounts of $0.35-0.41 \mathrm{mg} \mathrm{g}^{-1}$ and $1.3-1.9 \mathrm{mg} \mathrm{g}^{-1}$, respectively (Kuleyin 2006).

In a study conducted by Lemić et al. (2007), clinoptilolite modified by stearyl dimethylbenzyl ammonium chloride (SDBAC) was used to remove a few organic compounds: phenanthracene, fluorene, fluoranthene, pyrene and benz[a]anthracene. A concentrated solution of a mixture of selected polycyclic aromatic hydrocarbons (PAHs) in acetone was prepared. Five grams of the organo-clinoptilolite samples was added to 500 $\mathrm{cm}^{3}$ of PAHs' solution with the concentration $10 \mu \mathrm{g}$ per $\mathrm{dm}^{3}$ of the individual PAHs. The samples were shaken and centrifuged. The concentration was measured by high pressure liquid chromatography. Fluoranthene was removed first $\left(0.064 \mathrm{mg} \mathrm{g}^{-1}\right)$. The amounts of the other adsorbed PAHs decreased in the order: pyrene $\left(0.059 \mathrm{mg} \mathrm{g}^{-1}\right)$, fluorine $\left(0.044 \mathrm{mg} \mathrm{g}^{-1}\right)$ and phenanthrene (0.04 $\left.\mathrm{mg} \mathrm{g}^{-1}\right)$ (Lemić et al. 2007). 
TABLE 2

Comparison of methods and materials used for zeolites' modifications. Cp - Clinoptilolite, Na-P1 Syntetic zeolite Na-P1.

\begin{tabular}{|c|c|c|c|}
\hline Zeolite & Modification method & Materials & References \\
\hline \multirow{2}{*}{$\tilde{u}$} & \multirow{2}{*}{$\begin{array}{l}\text { Zeolite samples with grain size } 0.5 \mathrm{~mm} \text { were } \\
\text { treated with } 1 \mathrm{~mol} / \mathrm{L} \text { NaCl solution. One } \\
\text { hundred milliliters of HDTMA or BDTDA } \\
\text { solution with a concentration of } 0.03 \mathrm{~mol} / \mathrm{L} \text { was } \\
\text { placed in a flask and } 10 \mathrm{~g} \text { of zeolite added. The } \\
\text { samples were shaken for } 24 \mathrm{~h} \text {, washing with } \\
\text { distilled water and dried at } 50^{\circ} \mathrm{C} \text { in an oven. }\end{array}$} & $\begin{array}{l}\text { HDTMA } \\
\text { (hexadecyl trimethyl } \\
\text { ammonium bromide) }\end{array}$ & \multirow{2}{*}{ 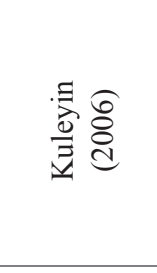 } \\
\hline & & $\begin{array}{l}\text { BDTDA } \\
\text { (benzyl tetradecyl } \\
\text { ammonium bromide) }\end{array}$ & \\
\hline$\tilde{u}$ & $\begin{array}{l}500 \mathrm{~g} \text { of clinoptilolite was added to } 0.5 \mathrm{~L} \text { of the } \\
\text { surfactant solutions. The samples were stirred } \\
\text { mechanically for } 30 \text { min and then washed with } \\
\text { redistilled water and dried. }\end{array}$ & $\begin{array}{l}\text { SDBAC } \\
\text { (stearyl dimethylbenzyl } \\
\text { ammonium chloride) }\end{array}$ & 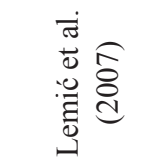 \\
\hline$\overline{\bar{n}}$ & $\begin{array}{l}\text { In order to obtain a surfactant coverage of } 1.0 \\
\text { ECEC, } 11.45 \mathrm{~g} \text { and } 24.4 \mathrm{mM} \text { of surfactant per } \\
100 \mathrm{~g} \text { of clinoptilolite and zeolite Na-P } 1 \text { was } \\
\text { used respectively. Each of the organo-zeolites } \\
\text { were prepared by mixing } 100 \mathrm{~g} \text { of zeolite with } \\
2000 \mathrm{~g} \text { of the surfactants' solutions at a } \\
\text { concentration of } 1.0 \text { ECEC. The samples were } \\
\text { stirred for } 8 \mathrm{~h} \text {, centrifuged and dried at } 60^{\circ} \mathrm{C} \text {. }\end{array}$ & $\begin{array}{l}\text { ODTMA (octadecyl-); } \\
\text { HDTMA } \\
\text { (heksadedyl-); TDTMA } \\
\text { (tetradecyl-); DDTMA } \\
\text { (dodecyl trimethyl-); } \\
\text { DODDMA (dioctadecyl-); } \\
\text { DHDDMA (dihexadecyl- } \\
\text { ); DTDDDMA } \\
\text { (ditetradecyl-); DDDDMA } \\
\text { (didodecyl } \\
\text { dimethylammonium } \\
\text { bromide) }\end{array}$ & 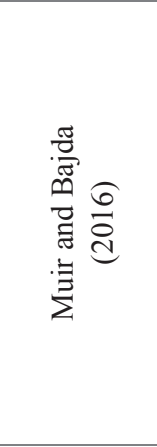 \\
\hline 嶽 & $\begin{array}{l}500 \mathrm{~mL} \text { of the solution of the surfactants with a } \\
\text { concentration of } 55 \mathrm{mmol} / \mathrm{L} \text { was mixed with } 10 \\
\mathrm{~g} \text { of mordenite at } 50^{\circ} \mathrm{C} \text { for } 4 \mathrm{~h} \text {. The samples } \\
\text { were cooled, centrifuged, washed with double- } \\
\text { distilled water and then dried in an oven at } 60^{\circ} \mathrm{C} \text {. }\end{array}$ & $\begin{array}{l}\text { TTMA (tetra-); BTMA } \\
\text { (butyl-); OTMA (octyl-); } \\
\text { DDTMA (dodecyl-); } \\
\text { HDTMA } \\
\text { (hexadecyltrimethyl- } \\
\text { ammonium bromide) }\end{array}$ & 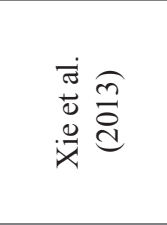 \\
\hline$\overline{\bar{t}}$ & $\begin{array}{l}500 \mathrm{~mL} \text { of the solution of surfactant - HDTMA } \\
\text { with a concentration of } 55 \mathrm{mmol} / \mathrm{L} \text { was mixed } \\
\text { with } 10 \mathrm{~g} \text { of Na-P } 1 \text { at } 50^{\circ} \mathrm{C} \text { for } 4 \mathrm{~h} \text {. Samples } \\
\text { were cooled, centrifuged, washed with double- } \\
\text { distilled water and dried in an oven at } 60^{\circ} \mathrm{C} \text {. }\end{array}$ & $\begin{array}{l}\text { HDTMA } \\
\text { (hexadecyltrimethyl- } \\
\text { ammonium bromide) }\end{array}$ & 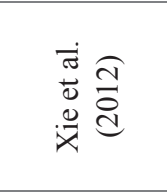 \\
\hline z & $\begin{array}{l}1 \mathrm{~g} \text { of } \mathrm{Na}-\mathrm{Y} \text { was added to a } 50 \mathrm{ml} \text { toluene } \\
\text { solution containing } 500 \mu \mathrm{mol} \text { OTS. The solution } \\
\text { was stirred for } 30 \mathrm{~min} \text { and then separated with a } \\
0.45 \mu \mathrm{m} \text { filter. The solid was washed with } \\
\text { ethanol anhydrous and chloroform. The sample } \\
\text { was dried in an oven at } 110^{\circ} \mathrm{C} \text { for } 5 \mathrm{~h} \text {. }\end{array}$ & $\begin{array}{l}\text { OTS } \\
\text { (n-octadecyltrichloro- } \\
\text { silane) }\end{array}$ & 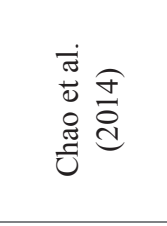 \\
\hline 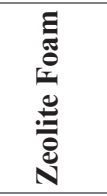 & $\begin{array}{l}\text { MOF- } 199 \text { with a concentration of } 5 \mathrm{mg} / \mathrm{mL} \text { and } \\
\text { zeolite foam was placed in an ultrasonic bath. } \\
\text { The sample was removed from the solution and } \\
\text { dried, under } \mathrm{N}_{2} \text { flow for } 6 \mathrm{~h} \text { and then heated in } \\
\text { an oven at } 100^{\circ} \mathrm{C} \text {. }\end{array}$ & $\begin{array}{l}\text { MOF-199 } \\
\text { (metal organic framwork) }\end{array}$ & 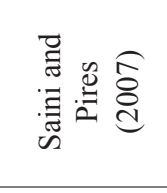 \\
\hline
\end{tabular}


The sorption efficiency of Verva, biodiesel and used oil on raw clinoptilolite was analyzed by Bandura et al. (2015). Oil stains were placed in Petri dishes covered with $5 \mathrm{~g}$ portions of clinoptilolite. The weight ratio of oil to the sorbent ranged from $0.25-2.0$. After $24 \mathrm{~h}$, the samples were placed on a lignin layer to remove the excess oil. The amount of sorbed oil was analyzed by a Perkin Elmer 2000 CHN analyzer. The sorption involved mesopores' filling and external surface coverage. Sorption capacity depended on the textural parameters of the zeolite and the physicochemical properties of the petroleum products, such as the density. Sorption capacities for clinoptilolite reached approximately $0.36 \mathrm{~g} \mathrm{~g}^{-1}$ for the used oil, $0.27 \mathrm{~g} \mathrm{~g}^{-1}$ for the biodiesel and $0.41 \mathrm{~g} \mathrm{~g}^{-1}$ for the Verva (Bandura et al. 2015).

Unmodified clinoptilolite and clinoptilolite modified by surfactants such as octadecyltrimethyl ammonium bromide (ODTMA), hexadecyltrimethyl ammonium bromide (HDTMA), tetrdecyltrimethyl ammonium bromide (TDTMA), dodecyltrimethyl ammonium bromide (DDTMA), dioctadecldimethyl ammonium bromide (DODDMA), dihexadecyldimethyl ammonium bromide (DHDDMA), ditetradecyldimethyl ammonium bromide (DTDDDMA) and diodecyldimethyl ammonium bromide (DDDDMA) were used to sorb Petro EuroSuper 95, Ekodiesel, engine oil and used engine oil, as described by Muir and Bajda (2016). The classical Westinghouse method of absorbability was used in the experiments. Drops of petroleum compounds were added to the sample of dry zeolite/organo-zeolite with a known weight until the point of maximum saturation was reached. In the case of engine oil and used engine oil, surface modification improved sorption efficiency due to the high viscosity of the petroleum compound. Diesel and used engine oil were preferably removed from the solution by zeolite $\mathrm{Cp}$ and its modifications. Unmodified Cp and DTDDMA-Cp were the best sorbents and removed 0.34 and $0.33 \mathrm{~g} \mathrm{~g}^{-1}$ of petrol, respectively. In the case of Ekodiesel, the highest sorption capacity occurred for DTDDMA-Cp $\left(0.39 \mathrm{~g} \mathrm{~g}^{-1}\right)$, and the lowest for HDTMA-Cp $\left(0.29 \mathrm{~g} \mathrm{~g}^{-1}\right)$. The best sorbents were DTDDMA-Cp and DHDDMA-Cp $\left(0.43 \mathrm{~g} \mathrm{~g}^{-1}\right)$, while the worst was TDTMA-Cp $\left(0.40 \mathrm{~g} \mathrm{~g}^{-1}\right)$ in the case of engine oil. Used engine oil was more effectively sorbed by Cp-organo-zeolites than unmodified Cp (Muir and Bajda 2016).

\subsection{Mordenite}

Mordenite modified by tetratrimethylammonium bromide (TTMA), butyltrimethylammonium bromide (BTMA), octyltrimethylammonium bromide (OTMA), dodecyltrimethylammonium bromide (DDTMA), and hexadecyltrimethylammonium bromide (HDTMA) was examined by Xie et al. (2013) in the case of humic acid sorption, phenol and naphthalene. The pollutants were added to distilled water and then mixed with the modified zeolites. The samples were shaken for $24 \mathrm{~h}$ and centrifuged. The concentration of organic pollutants was measured with a UV-vis spectrophotometer. The increase in chain length of the surfactant caused an increase in the removal of organic compounds. The only varying case was that of naphthalene. The removal efficiencies followed the order: humic acid $>$ phenol $>$ naphthalene. The sorption efficiency depended upon the chain length, surfactant coverage, the chain conformation and $\mathrm{pH}$ (Xie et al. 2013). 


\subsection{Na-P1}

Synthetic zeolite Na-P1 was examined in the case of sorption VOCs such as benzene, toluene, o-xylene and p-xylene. To prepare a benzene, toluene, xylene (BTX) solution, $50 \mathrm{mg} / \mathrm{g}$ of each was added to the distilled water. The sorption experiments were performed in closed glass vials using $0.5 \mathrm{~g}$ of the adsorbent and $10 \mathrm{~mL}$ of BTX solutions. The samples were placed into an SI 500 incubator and shaken at a temperature of $20^{\circ} \mathrm{C}$, then centrifuged. The concentration of the BTX was analyzed using gas chromatography. Sorption equilibrium was achieved after $24 \mathrm{~h}$. The pseudo-second-order model describes the adsorption of BTX by Na-P1. The sorption efficiency increased in the following order: benzene $>$ toluene $>$ p-xylene $>0$-xylene. The amount of removed hydrocarbons, expressed as the sum of BTX, reached $0.34 \mathrm{~g}$ by $1 \mathrm{~g}$ of zeolite Na-P1. The higher the initial concentration of hydrocarbon, the higher the sorption efficiency (Bandura et al. 2017b).

Na-P1 was also analyzed as a sorbent of Petrol EuroSuper 95, Ekodiesel, engine oil and used engine oil. The sorption efficiency of raw Na-P1 and Na-P1 modified by ODTMA, HDTMA, TDTMA, DDTMA, DODDMA, DHDDMA, DTDDMA and DDDDMA was measured. The classical Westinghouse method of absorbability was used in the experiments. Drops of petroleum compounds were added to the sample of dry zeolite/organo-zeolite with a known weight until the point of maximum saturation was reached. Na-P1 and its modifications are better sorbents of petrochemicals than clinoptilolite and $\mathrm{Cp}$-organo-zeolites, because of the highly developed surface area and a five-times-higher participation of mesopores than in natural zeolites. Organic modifications, in most cases, did not improve the sorption properties, which were determined by the viscosity of the petroleum liquid and the participation of mesopores. Diesel and used engine oil were preferably removed by Na-P1 and its modifications. Unmodified Na-P1 and DDTMA-Na-P1 were the best sorbents and removed 0.5 and $0.49 \mathrm{~g} \mathrm{~g}^{-1}$ of petrol, respectively. The highest values of sorption capacity were achieved for unmodified Na-P1 (0.55 $\left.\mathrm{g} \mathrm{g} \mathrm{g}^{-1}\right)$, TDTMA-Na-P1 $\left(0.5 \mathrm{~g} \mathrm{~g}^{-1}\right)$ and DDTMA-Na-P1 $\left(0.49 \mathrm{~g} \mathrm{~g}^{-1}\right)$ in the case of Ekodiesel. The best sorbents of engine oil were TDTMA-Na-P1 $\left(0.51 \mathrm{~g} \mathrm{~g}^{-1}\right)$ and DDTMA-Na-P1 $\left(0.51 \mathrm{~g} \mathrm{~g}^{-1}\right)$. The average sorption capacity of used engine oil reached $0.53 \mathrm{~g} \mathrm{~g}^{-1}$ of the removed used engine oil. In the case of engine oil and used engine oil, surface modification improved the sorption efficiency, because of its high viscosity (Muir, Bajda 2016).

Zeolite Na-P1 was used as a sorbent of Verva, biodiesel and used oil, with the results described by Bandura et al. (2015). Oil stains were placed in Petri dishes covered with $5 \mathrm{~g}$ portions of each sorbent. The weight ratio of oil to the sorbent ranged from $0.25-2.0$. After $24 \mathrm{~h}$, the samples were placed on a lignin layer to remove the excess oil. The amount of sorbed oil was analyzed with a Perkin Elmer 2000 CHN analyzer. The sorption involved mesopores' filling and external surface coverage. The sorption capacity depended on the textural parameters of the zeolites and the physicochemical properties of the petroleum products such as the density. Zeolite Na-P1 had the larger sorption capacities than natural zeolite and $\mathrm{Na}-\mathrm{X}$, and removed around $0.91 \mathrm{~g} \mathrm{~g}^{-1}$ of used oil and $0.86 \mathrm{~g} \mathrm{~g}^{-1}$ of Verva and biodiesel (Bandura et al. 2015).

Na-P1 modified by HDTMA was also examined by Xie et al. (2013) as a sorbent of phenol, p-chlorophenol, bisphenol A, aniline, nitrobenzene and naphthalene. The materials 
were mixed with aqueous solutions containing the organic pollutants' initial concentrations, and then shaken for $24 \mathrm{~h}$ and centrifuged or filtrated. The concentration of organic compounds was measured with a UV-vis spectrophotometer. The sorption capacity depended on the $\mathrm{pH}$. The removal of ionizable compounds depended upon the interaction of the phenol group with the positively charged "head" of the surfactant. The preferred adsorbed pollutant was bisphenol A. The removal of the non-ionizable compounds was a single partitioning process into the surfactant bilayer. The pollutant absorbed first was naphthalene (Xie et al. 2012).

\section{4. $\mathrm{Na}-\mathrm{X}$}

$\mathrm{Na}-\mathrm{X}$ was used as the sorbent of petrochemicals (Verva, biodiesel and used oil) by Bandura et al. (2015). Oil stains were placed in Petri dishes covered with $5 \mathrm{~g}$ portions of each sorbent. The weight ratio of oil to the sorbent ranged from $0.25-2.0$. After $24 \mathrm{~h}$, the samples were placed on a lignin layer to remove the excess oil. The amount of sorbed oil was analyzed with a Perkin Elmer 2000 CHN analyzer. The sorption involved mesopores' filling and external surface coverage. Sorption capacity depended upon the textural parameters of the zeolites and the physicochemical properties of the petroleum products such as the density. Na-X removed around $0.79 \mathrm{~g} \mathrm{~g}^{-1}$ of used oil and biodiesel, and $0.75 \mathrm{~g} \mathrm{~g}^{-1}$ of Verva. Synthetic zeolites were better sorbents than clinoptilolite (Bandura et al. 2015).

\subsection{Na-Y}

$\mathrm{Na}-\mathrm{Y}$ and OTS-Na-Y (n-octadecyltrichlorosilane) were analyzed as the sorbents for benzene, toluene, ethylbenzene, propylbenzene, $\mathrm{n}$-Pentanol, trichlorom ethane and $\mathrm{m}$ Cresol by Chao et al. (2011). One gram of Na-Y or Na-Y modified by OTS was added to $50 \mathrm{ml}$ of distilled water and mixed in a Teflon centrifuge tube. The compound was then added to the solution to provide the concentration of approximately $20-80 \%$ water solubility. The samples were shaken for $48 \mathrm{~h}$ and then centrifuged. The concentrations of organic compounds were analyzed using a gas chromatograph or an ultraviolet spectrometer (phenol and m-cresol). In the case of raw Na-Y, a weak affinity to benzene, toluene, ethylbenzene and propylbenzene was seen, because of a low $\mathrm{Si} / \mathrm{Al}$ ratio of Na-Y zeolite. The compounds have a relatively low water solubility, which results in low adsorption capacities on the Na-Y zeolite. The maximum sorption of benzene, toluene, ethylbenzene and propylbenzene were $4.2 \mathrm{mg} \mathrm{g}^{-1}, 3.8 \mathrm{mg} \mathrm{g}^{-1}, 1.9 \mathrm{mg} \mathrm{g}^{-1}$ and $0.5 \mathrm{mg} \mathrm{g}^{-1}$, respectively. N-pentalol displayed a high adsorption capacity, because of the ability to form a hydrogen bond with the oxygen atom on the mineral's surface. The maximum amount of removed n-Pentanol was $2.1 \mathrm{mg} \mathrm{g}^{-1}$. Trichlorom ethane has a relatively high water solubility; however, because of the molecular structure, it lacks the affinity with the zeolite surface. The highest amount of removed trichlorom ethane reached $0.25 \mathrm{mg} \mathrm{g}^{-1}$. M-Cresol has a high adsorption efficiency because of the ability to form a hydrogen bond with the zeolite's surface. The maximum amount of sorption was $2.9 \mathrm{mg} \mathrm{g}^{-1}$. Na-Y modified by OTS was a better sorbent than unmodified $\mathrm{Na}-\mathrm{Y}$. In the case of benzene, toluene, ethylbenzene and propylbenzene the sorption mechanism involved partitioning. Those compounds have 
a low water solubility, which results in low adsorption capacities on the Na-Y zeolite. The n-octadecyltrichlorosilane covers only the external surface, so only a small amount of the compounds could be adsorbed on the internal pore surface. The maximum amounts of sorption of benzene, toluene, ethylbenzene and propylbenzene were $13 \mathrm{mg} \mathrm{g}^{-1}, 16 \mathrm{mg} \mathrm{g}^{-1}$, $24 \mathrm{mg} \mathrm{g}^{-1}$ and $4 \mathrm{mg} \mathrm{g}^{-1}$, respectively. N-pentanol displays a high adsorption capacity, because of the ability to form a hydrogen bond with the oxygen atom on the mineral surface. The highest amount of sorption was $21.5 \mathrm{mg} \mathrm{g}^{-1}$. Trichlorom ethane has a low affinity to Na-Y; however, because of the modification the partitioning effect occurs. The maximum amount of sorption was $11 \mathrm{mg} \mathrm{g}^{-1}$. The high adsorption efficiency is due to the fact that $\mathrm{m}$-Cresol is able to adsorb onto the hydrophilic internal surfaces. The highest amount of removed m-Cresol reached $24.5 \mathrm{mg} \mathrm{g}^{-1}$ (Chao et al. 2014).

\subsection{Zeolite Foam}

Zeolite Foam (ZF) and Zeolite MOF Foam (ZMF) were analyzed as a sorbent of benzene, n-hexane and cyclohexane by Saini and Pires (2011). The adsorption of VOCs together with adsorption isotherms were studied and measured by the gravimetric adsorption technique. Each sample was degassed at $120^{\circ} \mathrm{C}$ for $2 \mathrm{~h}$, with a ramp of $10^{\circ} \mathrm{C}$ per min under the dynamic vacuum. Adsorption efficiency depends on the specific surface area of the used material. ZMF was a better sorbent than ZF. In the case of zeolite foam, $\mathrm{n}$-hexane was the most removed compound and showed maximum adsorption even at a low pressure. Cyclohexane was the least effective sorbed compound. In the case of the modified zeolite, the situation reverses. Benzene was adsorbed in the greatest amount. N-Hexane and cyclohexane were removed in similar amounts (Saini, Pires 2011).

\section{Conclusions}

Inexpensive, effective, readily available, natural and synthetic zeolites can be used instead of commercially available sorbents (e.g. activated carbon) for the removal of organic compounds and petrochemicals. In this paper, a wide range of natural and synthetic zeolites have been studied. The comparisons of the sorption properties between the various minerals were difficult because of inconsistencies in the data presentation (various modification methods, sorbent preparation and unconvincing testing methods). However, from the literature reviewed, a few zeolites that stand out for their high efficiency of organic compound removal were identified. The Materials chapter presents a summary of some of the highest adsorption capacities obtained by scientists in various research projects. The removal of $90-100 \%$ of organic contaminants from aqueous solution was reported for synthetic zeolite Na-P1 modified by organic surfactants (mostly quaternary ammonium salts, e.g. ODTMA, HDTMA). Ninety-eight percent of organic compounds were removed by clinoptilolite modified by SDBAC. Modification of clinoptilolite with BDTDA exhibits a much lower efficiency in the removal of organic compounds, depending on the process conditions, and the organic compound efficiency was $50-98 \%$. An objective of further academic and industrial studies should be to improve the chemical and physical stability of modified zeolites, which would allow their use on a larger scale. Sorption efficiency depends on many factors, such as surface modifications and the chain length of surfactants 
in the case of mordenite, which removed humic acid, phenol and naphthalene, and Na-P1 modified by HDTMA, which sorbed phenol, aniline or nitrobenzene. In this case, sorption capacity was also determined by the $\mathrm{pH}$ of the solution. In the situation of sorption petrochemicals by clinoptilolite, Na-P1 and its modification amounts of removed compounds depended on the participation of the mesopores of zeolites and the viscosity of the petrochemicals. Finally, in the case of Zeolite Foam and Zeolite MOF Foam, the sorption efficiency of VOCs was determined by the surface area of the used materials.

\section{References}

Alkan, M., Hopa, C., Yilmaz, Z., \& Guler, H. (2005). The effect of alkali concentration and solid/liquid ratio on the hydrothermal synthesis of zeolite NaA from natural kaolinite. Microporous and Mesoporous Materials, 86, 176-184. DOI: 10.1016/j.micromeso.2005.07.008.

Almeida, I. L., Antoniosi Filho, N. R., Alves, M. I., Carvalho, B. G., \& Coelho, N. M. (2012). Removal of BTEX from aqueous solution using Moringaoleifera seed cake. Environmental Technology, 33, 1299-1305. DOI: 10.1080/09593330.2011.621451.

Aivalioti, M., Pothoulaki, D., Papoulia, P., \& Gidarakos, E. (2012). Removal of BTEX, MTBE and TAME from aqueous solutions by adsorption onto raw and thermally treated lignite. Journal of Hazardous Materials, $207-$ 208, 136-146. DOI: 10.1016/j.hazmat.2011.04.084.

Apreutesei, R. E., Catrinescu, C., \& Teodosiu, C. (2008). Surfactant-modified natural Zeolites for environmental applications in water purification. Environmental Engineering and Management Journal, 7, 149-161.

Bandura, L., Woszczuk, A., Kołodyńska, D., \& Franus, W. (2017a). Application of Mineral Sorbents for Removal of Petroleum Substances: A Review. Minerals, 7, 1-25. DOI: 10.3390/min7030037.

Bandura, L., Kołodyńska, D., \& Franus, W. (2017b). Adsorption of BTX from aqueous solutions by Na-P1 zeolite obtained from fly ash. Process Safety and Environmental Protection, 109, 214-223. DOI: 10.1016.j.psep.2017.03.036.

Bandura L., Franus M., Józefaciuk G., \& Franus W. (2015). Syntetic zeolites from fly ash as effective mineral sorbents for land-based petroleum spills cleanup. Fuel, 147, 100-107. DOI: 10.1016/j.fuel.2015.01.067.

Bowman, R. S. (2003). Applications of surfactant-modified zeolites to environmental remediation. Microporous and Mesoporous Materials, 61, 43-56. DOI: 10.1016/S1387-1811(03)00354-8.

Chao, H.-P., Peng, C.-L., Lee, C.-K., \& Han, Y.-L. (2011). A study on sorption of organic compounds with different water solubilities on octadecyltrichlorosilane-modified NaY zeolite. Journal of the Taiwan Institute of Chemical Engineers, 43, 195-200. DOI: 10.1016/j.tice.2011.10.002.

Derkowski, A., Franus, W., Waniak-Nowicka, H., \& Czímerová, A. (2007). Textural properties vs. CEC and EGME retention of $\mathrm{Na}-\mathrm{X}$ zeolite prepared from fly ash at room temperature. International Journal of Mineral Processing, 82(2), 57-68. DOI: 10.1016/j.minpro.2006.10.001.

Franus, W., \& Wdowin, M. (2010). Removal of ammonium ions by selected natural and synthetic zeolites. Gospodarka Surowcami Mineralnymi - Mineral Resources Management, 26(4), 133-148.

Franus, W., Wdowin, M., \& Franus, M. (2014). Synthesis and characterization of zeolites prepared from industrial fly ash. Environmental Monitoring and Assessment, 186, 5721-5729. DOI: 10.1007/s10661-014-3815-5.

Gatta, G. D., Lotti, P., Nestola, F., \& Pasqual, D. (2012). On the high-pressure behavior of gobbinsite, the natural counterpart of the synthetic zeolite Na-P2. Microporous and Mesoporous Materials, 163, 259-269. DOI: 10.1016/j.micromeso.2012.07.005.

Grce, M., \& Pavelić, K. (2005). Antiviral properties of clinoptilolite. Microporous and Mesoporous Materials, 79 , 165-169. DOI: 10.1016/j.micromeso.2004.10.039.

Itabashi, K., Fukushima, T., \& Igawa, K. (1986). Synthesis and characteristic properties of siliceous mordenite. Zeolites, 6, 30 -34. DOI: 10.1016/0144-2449(86)90008-4.

Kibazohi, O., Yun, S. I., \& Anderson, W. A. (2004). Removal of Hexane in Biofilters Packed with Perlite and a Peat-Perlite Mixture. World Journal of Microbiology and Biotechnology, 20, 337-343. DOI: 10.1023/B:WIBI.0000033054.15023.71.

Kuleyin, A. (2006). Removal of phenol and 4-chlorophenol by surfactant-modified natural zeolite. Journal of Hazardous Materials, 144, 307-315. DOI:10.1016/j.hazmat.2006.10.036.

Lee, S. M., \& Tiwari, D. (2012). Organo and inorgano-organo-modified clays in the remediation of aqueous solutions: An overview. Applied Clay Science, 67-68, 91-98. DOI: 10.1016/j.clay.2012.02.006. 
Lemic, J., Tomasevic-Canovic, M., Adamovic, M., Kovacevic, D., \& Milicevic, S. (2007). Competitive adsorption of polycyclic aromatic hydrocarbons on organo-zeolites. Microporous and Mesoporous Materials, 105, $317-$ 323. DOI: 10.1016/j.micromeso.2007.04.014.

Li, Z., \& Bowman, R. S. (1998). Sorption of Perchloroethylene by Surfactant-Modified Zeolite as Controlled by Surfactant Loading. Environmental Science and Technology, 32, 2278-2282. DOI: 10.1021/es971118r.

Mansouri, N., Rikhtegar, N., Panahi, H. A., Atabi, F., \& Shahraki B. K. (2013). Porosity, characterization and structural properties of natural zeolite - clinoptilolite - as a sorbent. Environment Protection Engineering, 39, 139-152. DOI:

Margeta, K., Zabukovec Logarn, N., Šiljeg, M., \& Farkas, A. (2013). Natural Zeolites in Water Treatment - How Effective is Their Use. Water Treatment, Dr. Walid Elshorbagy (Ed.), InTech, DOI: 10.5772/50738.

Mathur, A. K., Majumder, C. B., \& Chatterjee, S. (2007). Combined removal of BTEX in air stream by using mixture of sugar cane bagasse, compost and GAC as biofilter media. Journal of Hazardous Materials, 148, 64-74. DOI: 10.1016/j.jhazmat.2007.02.030.

Meininghaus, C. K. W., \& Prins, R. (2000). Sorption of volatile organic compounds on hydrophobic zeolites. Microporous and Mesoporous Materials, 35-36, 349-365. DOI: 10.1016/S1387-1811(99)00233-4.

Muir, B., \& Bajda, T. (2016a). Organically modified zeolites in petroleum compounds spill cleanup - Production, efficiency, utilization. Fuel Processing Technology, 149, 153-162. DOI: 10.1016/j. fuproc.2016.09.017.

Muir, B., Matusik, J., \& Bajda, T. (2016b). New insights into alkylammonium-functionalized clinoptilolite and Na-P1 zeolite: Structural and textural features. Applied Surface Science, 361, 242-250. DOI: 10.1016/j.apsusc.2015.11.116.

Ranck, J. M., Bowman, R. S., Weeber, J. L., Katz, L. E., \& Sullivan, J. (2005). BTEX removal from produced water using surfactant-modified zeolite. Journal of Environmental Engineering, 131, 434-442. DOI: 10.1061/(ASCE)0733-9372(2005)131:3(434).

Saini, V. K., \& Pires, J. (2017). Development of metal organic fromwork-199 immobilized zeolite foam for adsorption of common indoor VOCs. Journal of Environmental Sciences, 55, 321-330. DOI: 10.1016/j.jes.2016.09.017.

Sand, L. B. (1968). Synthesis of large-port and small port mordenites. In Molecular Sieves, Society of Chemical Industry, London, 71-77.

Szala, B., Bajda, T., Matusik, J., Zięba, K., \& Kijak, B. (2015). BTX sorption on Na-P1 organo-zeolite as a process controlled by the amount of adsorbed HDTMA. Microporous and Mesoporous Materials, 202, $115-$ 123. DOI: 10.1016/j.micromeso.2014.09.033.

Qin, X. S., Huang, G. H., \& Li, Y. P. (2008). Risk Management of BTEX Contamination in Ground Water - An Integrated Fuzzy Approach. Ground Water, 46, 5, 755-767. DOI: 10.1111/j.1745-6584.2008.00464.x.

Querol, X., Alastuey, A., Fernandez-Turiel, J. L., \& Lopez-Soler, A. (1995). Synthesis of zeolites by alcaline activation of ferro-aluminous fly ash. Fuel, 74, 1226-1231. DOI: 10.1016/0016-2361(95)00044-6.

Xie, J., Meng, W., Wu, D., Zhang, Z., \& Kong, H. (2012). Removal of organic pollutants by surfactant modified zeolite: Comparison between ionizable phenolic compounds and non-ionizable organic compounds. Journal of Hazardous Materials, 231-232, 57-63. DOI: 10.1016/j.hazmat.2012.06.035.

Xie, Q., Xie, J., Wang, Z., Wu, D., Zgang, Z., \& Kong, H. (2013). Adsorption of organic pollutants by surfactant modified zeolite as controlled by surfactan chain length. Microporous and Mesoporous Materials, 179, 144150. DOI: 10.1016/j.micromeso.2013.05.027.

Zhao, H., \& Vence, G. F. (1988). Sorption of trichloroethylene by organo-clays in the presence of humic substances. Water Research, 32, 3710-3716. DOI: 10.1016/S0043-1354(98)00172-9. 